\title{
Recomendações para a atuação dos fisioterapeutas na reanimação cardiopulmonar em pacientes adultos com COVID-19*
}

\author{
Recommendations for the contribution of physiotherapy during cardiopulmonary resuscitation \\ in adult patients with COVID-19*
}

\author{
MORAKAMI, Fernanda Kazmierski; ANDRADE, Flávio Maciel de²; KARSTEN, Marlus³; \\ em nome do Comitê COVID-19 da ASSOBRAFIR.
}

\begin{abstract}
Resumo
O presente documento apresenta recomendações para atuação do fisioterapeuta na reanimação cardiopulmonar em pacientes adultos com suspeita ou diagnóstico de COVID-19, apontando considerações principalmente aos cuidados específicos que devem ser adotados nesta situação clínica, os quais diferem das recomendações habituais. Tem como foco a preocupação com a proteção dos profissionais de saúde atuantes na reanimação cardiopulmonar e a melhor assistência aos pacientes, minimizando riscos, padronizando ações e recomendando condutas. Dentre as principais recomendações, há indicação de não desconexão da assistência ventilatória mecânica, e de uso de parâmetros ventilatórios específicos, além da abordagem da posição prona. Sabemos ainda que, dentro da atual situação mundial frente à pandemia COVID-19, é possível que estudos futuros possam contribuir para consolidar e acrescentar as recomendações apresentadas neste documento.
\end{abstract}

Palavras-chave: Fisioterapia; Reanimação Cardiopulmonar; COVID-19.

* Revisado por membros do Comitê COVID-19 da ASSOBRAFIR, nomeado por meio do memorando N003/2020. Esta publicação é uma atualização da Comunicação Oficial "Recursos e técnicas fisioterapêuticas que devem ser utilizadas com cautela ou evitadas em pacientes com COVID-19”, chancelada pelo Comitê COVID-19 da ASSOBRAFIR, originalmente escrita pelos mesmos autores e divulgada em 26/03/2020 no endereço eletrônico https://assobrafir.com. br/wp-content/uploads/2020/03/ASSOBRAFIR COVID-19 RCP V2-1.pdf

1 Universidade Pitágoras-Unopar EaD, Londrina, Paraná, Brasil. Universidade Anhanguera-Uniderp EaD, Londrina, Paraná, Brasil. Grupo de Estudos em Terapia Intensiva, Universidade Estadual de Londrina (UEL), Londrina, Paraná, Brasil. Email: fermorakami@gmail.com. FKM - https://orcid.org/0000-0002-2214-9821

2 Universidade Católica de Pernambuco, Recife, Pernambuco, Brasil. FMA - https://orcid.org/0000-0002-9918-2662

3 Departamento de Fisioterapia e Programa de Pós-Graduação em Fisioterapia, Universidade do Estado de Santa Catarina (UDESC), Florianópolis, Santa Catarina, Brasil. Programa de Pós-Graduação em Ciências da Reabilitação, Universidade Federal de Ciências da Saúde de Porto Alegre (UFCSPA), Porto Alegre, Rio Grande do Sul, Brasil. MK - https://orcid. org/0000-0002-2476-7981 


\section{Abstract}

The current document provides recommendations for the contribution of physiotherapy during cardiopulmonary resuscitation (CPR) in adults with suspected or confirmed COVID-19, highlighting the differences related to this clinical situation compared to usual recommendations. It focuses on preventing the contamination of health professionals while providing the best care to patients. Standardized procedures are recommended in order to reduce the risk of contamination by health professionals. The main recommendations are to use specific ventilator settings and not to disconnect the patient from the ventilator during the procedure, besides recommendations to CPR while in prone position. In the current pandemic the world is facing, it is possible that future studies can contribute to consolidate and add to the recommendations presented in the current document.

Keywords: Physiotherapy; Cardiopulmonary Resuscitation; COVID-19.

\section{Objetivo}

O objetivo do presente documento é orientar fisioterapeutas na assistência durante a parada cardiorrespiratória em pacientes com suspeita ou diagnóstico de COVID-19.

\section{Contextualização}

A ressuscitação cardiopulmonar (RCP) é a situação clínica de maior prioridade assistencial, uma vez que quanto mais tardar do início das manobras de ressuscitação, pior será o prognóstico esperado para este paciente. Além disso, por se tratar de uma situação de extrema tensão e estresse para a equipe multiprofissional, se faz necessário que as condutas e protocolos estejam bem definidos e esclarecidos. Com o início da pandemia da COVID-19, veio à tona a preocupação em relação aos protocolos de RCP, pois neste momento adiciona-se o alto risco de contaminação da equipe assistencial, ou seja, dos profissionais de saúde que estarão em contato direto com o paciente ${ }^{1,2}$. A Organização Mundial da Saúde listou diversos procedimentos considerados geradores de aerossóis e, entre estes, encontrase: intubação orotraqueal (IOT), ventilação manual com bolsa válvula máscara (BVM), aspiração aberta, desconexão do paciente do ventilador mecânico e a também as compressões torácicas. Tais procedimentos muitas vezes estão presentes no momento da RCP, evidenciando assim a importância de se considerar maiores cuidados quando a assistência está sendo prestada na presença de suspeita ou diagnóstico de COVID-19³.

Tendo em vista o envolvimento de procedimentos considerados geradores de aerossóis, a RCP em casos suspeitos ou confirmados de COVID-19 deve seguir os protocolos da American Heart Association (AHA), com algumas recomendações específicas. Para que se possa oferecer um atendimento de excelência, recomenda-se a leitura complementar do protocolo de RCP da AHA.

As causas mais comuns de parada cardiorrespiratória em pacientes com diagnóstico de COVID-19 são o choque cardiogênico, a hipóxia e o uso prolongado de medicações, as quais devem ser revertidas o mais rápido possível, pois estão associadas a piores prognósticos clínicos ${ }^{4}$.

Ao socorrer um paciente com suspeita ou confirmação de COVID-19, o profissional deve informar a todos os envolvidos sobre o potencial risco de transmissão do coronavírus. Também se aconselha a presença do menor número possível de pessoas na assistência ao paciente, e o uso de pressão negativa na sala. É importante considerar que haja uma equipe de suporte fora do ambiente da RCP com o objetivo de auxiliar a equipe atuante com oferta de medicações, equipamentos ou qualquer outro material ou equipamento necessário. 


\section{Uso de equipamentos de proteção individual (EPIs) para assistência na COVID-19}

Atualmente sugere-se o uso de gorro, máscaras N95 ou PFF2, luvas, avental impermeável, capote, óculos de proteção e/ou protetor facial. A paramentação adequada do profissional deve ser realizada antes de qualquer procedimento, mesmo que isso retarde o início da RCP, uma vez que a segurança da equipe é fundamental. Este procedimento deve ser realizado antes da entrada do profissional no local de assistência ao paciente e os equipamentos devem estar dispostos nos carrinhos de emergência do setor. As compressões torácicas só podem ser iniciadas se TODOS estiverem devidamente paramentados. Para evitar auto contaminação, remova os EPIs e higienize os materiais utilizados de acordo com as orientações e descarte-os em local adequado ${ }^{5}$.

\section{Uso de aspirador de secreções}

Se o aspirador de secreções for utilizado, a extremidade da mangueira deve ser protegida (ex.: com luva descartável) e, em hipótese alguma, deve ser colocada sobre a cama do paciente ou outras superfícies próximas. No caso de pacientes com vias aéreas artificiais, deve ser utilizado o sistema fechado de aspiração ${ }^{6}$.

Adicionalmente às recomendações padronizadas para a RCP, existem cuidados a serem tomados na assistência de um paciente com suspeita ou diagnóstico de COVID-19.

\section{Ventilações de resgate}

As ventilações manuais devem ser realizadas somente em casos de extrema necessidade. Nesses casos, use máscara facial, filtro adequado (High Efficiency Particulate Air - HEPA), BVM e cânula de Guedel. O procedimento deve ser realizado por dois profissionais, não permitindo escape de ar durante a oferta ventilatória. A IOT, deve ocorrer o mais rápido possível, sendo realizada pelo profissional (médico) mais experiente. Até que a IOT aconteça, deve-se manter ou aumentar a oferta de oxigênio destinada ao paciente pelo sistema de oferta de oxigênio em uso (catéter de baixo fluxo, máscara facial ou máscara com reservatório).

Se o paciente já estiver em ventilação mecânica invasiva, é possível utilizar a ventilação manual do próprio ventilador, ou adequar os parâmetros ventilatórios da seguinte forma ${ }^{5-8}$ :

- $\mathrm{FR}=10-12 \mathrm{ipm}$

- $\mathrm{FiO}_{2}=100 \%$

- Relação I:E = 1:2

- Tempo inspiratório $=1$ segundo

- $\mathrm{PEEP}=5 \mathrm{cmH}_{2} \mathrm{O}$. Na literatura, observa-se sugestões para utilização de ZEEP (PEEP $=0$ $\mathrm{cmH}_{2} \mathrm{O}$ ) para favorecer as compressões torácicas

- Sensibilidade inspiratória ajustada a fim de evitar disparos adicionais (off ou o menos sensível possível), devido às compressões torácicas realizadas durante a RCP

- Alarme de pressão máxima de vias aéreas (pressão de pico) ajustado em torno de $60 \mathrm{cmH}_{2} \mathrm{O}$

É importante salientar que há variação de configuração entre os diversos fabricantes de ventiladores mecânicos, sendo que alguns parâmetros citados podem não ser aplicáveis de forma simultânea, devendo ser ajustados de acordo com as variáveis de controle disponíveis para ajuste.

Embora não haja um modo ventilatório de escolha e algumas indicações na literatura de uso de modo a pressão controlada, deve-se garantir um volume corrente adequado, em torno de $6 \mathrm{ml} / \mathrm{Kg}$ de 
peso predito para o paciente. Se for necessário usar a BVM, recomenda-se ventilar um volume igual ou maior que $600 \mathrm{~mL}$. Sempre que seu uso for inevitável, recomenda-se clampear o tubo na transição para a BVM (EVITE ao máximo a dispersão de aerossóis). Caso a opção seja realizar ventilações manuais com o uso do ventilador mecânico, deve-se acionar o botão específico para a realização dos ciclos respiratórios, sempre que houver essa opção no equipamento ${ }^{5-7}$.

Há, ainda, ventiladores mecânicos que têm um modo ventilatório específico para utilização na $\mathrm{RCP}$, com parâmetros ventilatórios pré-determinados e que realizam as ventilações de forma assíncrona com as compressões torácicas, assim como aparelhos de compressão torácica mecânica, que também podem ser adotados.

\section{RCP em posição prona ${ }^{8-10}$}

Nos casos de parada cardiorrespiratória durante posicionamento em prona, sem possibilidade de mudança imediata para posição supina, recomenda-se a realização das compressões torácicas em posição prona, mantendo as mãos entre as escápulas.

Se necessário, a manobra de contrapressão pode ser realizada por outro profissional. O retorno à posição supina é indicado uma vez que a equipe julgue a ineficácia das compressões torácicas em posição prona, desde que esta manobra seja realizada com segurança, evitando assim a dispersão de aerossóis. Neste caso a desfibrilação deve ser realizada entre a $7^{\mathrm{a}}$ e $10^{\mathrm{a}}$ vértebras torácicas.

\section{Considerações Finais}

É importante considerar que para obter um melhor prognóstico ao paciente após uma PCR, a equipe multiprofissional deve estar treinada e sincronizada em relação as condutas a serem realizadas.

Tratando-se de uma situação pandêmica e de um vírus de alta infectividade, traz à tona a necessidade de readequações e considerações específicas no intuito de proteger o profissional da saúde atuante e oferecer uma assistência segura e efetiva ao paciente.

Nos reservamos de possíveis atualizações futuras, uma vez que as recomendações trazidas por este documento se baseiam na opinião de especialistas e nos direcionamentos de entidades internacionais voltadas para este assunto.

\section{Referências}

1. WHO. Clinical management of severe acute respiratory infection (SARI) when COVID-19 disease is suspected. Geneva: World Health Organization; 2020 [cited 2020 Jun 08]. Available from: https://www. who.int/publications-detail/clinical-management-of-severe-acute-respiratory-infection-when-novelcoronavirus-(ncov)-infection-is-suspected

2. Brasil. Ministério da Saúde. Coronavírus: profissionais e gestores de saúde. Brasília: Ministério da Saúde; 2020 [cited 2020 Jun 08]. Available from: https://coronavirus.saude.gov.br/.

3. WHO. Modes of transmission of virus causin COVID-19: implications for IPC precaution recommendations. Geneva: World Health Organization; 2020 [cited 2020 Jun 08]. Available from: https://www.who.int/news-room/commentaries/detail/modes-of-transmission-of-virus-causingcovid-19-implications-for-ipc-precaution-recommendations 
4. Chahar P, Marciniak D. Cardiopulmonary ressuscitation in COVID-19 patients. Cleve Clin J Med. 2020 Jun 11. doi: 10.3949/ccjm.87a.ccc040. Online ahead of print.

5. Resuscitation Council UK. Guidance for the resuscitation of COVID-19 patients in Hospital. London: Resuscitation Council UK; 2014-2020. Available from: https://www.resus.org.uk/media/statements/ resuscitation-council-uk-statements-on-covid-19-coronavirus-cpr-and-resuscitation/

6. American Heart Association. Coronavirus (COVID-19) Resources for CPR Training. Dallas: American Heart Association; 2020. Available from: https://cpr.heart.org/en/resources/coronaviruscovid19-resources-for-cpr-training.

7. Guimarães HP, Timerman S, Correa T, Rodrigues RR, Freitas AP, Rea Neto A. Recomendações para Ressuscitação Cardiopulmonar (RCP) de pacientes com diagnóstico ou suspeita de COVID-19-ABRAMEDE/ AMIB/SBC. [Porto Alegre]: Associação Brasileira de Medicina de Emergência; 2020. Available from: http:// abramede.com.br/wp-content/uploads/2020/03/RCP-ABRAMEDE-SBC-AMIB-05-210320.pdf

8. Edelson DP, Sasson C, Chan PS, Atkins DL, Aziz K, Becker LB, et al, Interim Guidance for Life Support for COVID-19. Circulation. 2020 Jun 23;141(25):e933-e943. doi: 10.1161/CIRCULATIONAHA.120.047463. Epub 2020 Apr 9.

9. Bamford P, Denmade C, Newmarch C, Shirley P, Singer B, Webb S, et al. Guidance for prone positioning in adult critical care. Prepared on behalf of the Intensive Care Society and Faculty of Intensive Care Medicine. London: Intensive Care Society; 2019 Nov. Available from: https://www.ficm.ac.uk/sites/ default/files/prone position in adult critical care 2019.pdf

10. Barker J, Koeckerling D, West R. A need for prone position CPR guidance for intubated and non-intubated patients during the COVID-19 pandemic. Resuscitation. 2020 Jun;151:135-136. doi: 10.1016/j.resuscitation.2020.04.029. Epub 2020 May 1.

Submissão em: 23/06/2020

Aceite em: 15/07/2020 